\title{
2 An Ecological Study to Investigate Links Between Atmospheric 3 Pollutants From Farming and SARS-CoV-2 Mortality
}

\author{
4 Paolo Contiero ${ }^{1}$, Alessandro Borgini ${ }^{1,12 *}$, Martina Bertoldi ${ }^{1}$, Anna Abita ${ }^{2}$, Giuseppe Cuffari ${ }^{3}$, Paola Tomao ${ }^{4}$, Maria \\ 5 Concetta D'Ovidio ${ }^{4}$, Stefano Reale ${ }^{5}$, Silvia Scibetta ${ }^{5}$, Giovanna Tagliabue ${ }^{6}$, Roberto Boffi ${ }^{7}$, Vittorio Krogh ${ }^{8}$, Fabio \\ 6 Tramuto, 10 , Carmelo Massimo Maida ${ }^{9,10}$, Walter Mazzucco9,10,11 and the “SARS-CoV-2 and Environment Working \\ 7 Group $^{\prime * * *}$
}

1 Environmental Epidemiology Unit, Fondazione IRCCS Istituto Nazionale dei Tumori, 20133 Milan, Italy; alessandro.borgini@istitutotumori.mi.it

2 UOC Qualità dell'Aria, ARPA Sicilia, 90146 Palermo, Italy; abita@arpa.sicilia.it

3 Reporting Ambientale, Salute e Ambiente, ARPA Sicilia; 90146 Palermo, Italy; gcuffari@arpa.sicilia.it

4 Inail-Dipartimento di medicina, epidemiologia, igiene del lavoro ed ambientale, 00078 Monte Porzio Catone (Roma), Italy; p.tomao@inail.it

5 Laboratorio Tecnologie Diagnostiche Innovative Area Biologia Molecolare, Istituto Zooprofilattico Sperimentale della Sicilia, Via Rocco Dicillo 3, 90129 Palermo, Italy; stefano.reale@izssicilia.it

6 Cancer Registry Unit, Fondazione IRCCS Istituto Nazionale dei Tumori, 20133 Milan, Italy; giovanna.tagliabue@istitutotumori.mi.it

7 Respiratory Disease Unit, Fondazione IRCCS Istituto Nazionale Tumori, 20133 Milan, Italy; roberto.boffi@istitutotumori.mi.it

8 Epidemiology and Prevention Unit, Fondazione IRCCS Istituto Nazionale dei Tumori, 20133 Milan, Italy; vittorio.krogh@istitutotumori.mi.it

9 Department of Health Promotion, Mother and Child Care, Internal Medicine and Medical Specialties (PROMISE) “G. D'Alessandro” - University of Palermo, 90127 Palermo, Italy; walter.mazzucco@unipa.it

10 Regional Reference Laboratory of West Sicily for the Emergency of COVID-19, Clinical Epidemiology Unit, University Hospital "Paolo Giaccone”, 90127 Palermo, Italy;

11 Division of Biostatistics and Epidemiology, Cincinnati Children's Hospital Medical Centre, Cincinnati, Ohio 45229, USA

12 International Society of Doctors for Environment (ISDE), 52100 Arezzo, Italy

* Correspondence: alessandro.borgini@istitutotumori.mi.it; Tel.: +390223903536

**SARS-CoV-2 and Environment Working Group:AlessandroCau ${ }^{1}$, Viviana Perotti ${ }^{6}$,Vincenzo Restivo, ${ }^{90}$, Claudio Costantino 9,10 , Giuseppe Lanza ${ }^{9}$, Maurizio Zarcone ${ }^{10}$, Adalberto Cavalleri ${ }^{8}$, Chiara Veronese ${ }^{7}$, Cinzia De Marco ${ }^{13}$, ArioRuprecht ${ }^{7}$

${ }_{13}$ Biomarkers Unit, Fondazione IRCCS Istituto Nazionale dei Tumori, 20133 Milan, Italy;

34 Abstract: Exposure to atmospheric particulate matter and nitrogen dioxide has been 35 linked to SARS-CoV-2 infection and death. We hypothesized that an interaction between SARS-CoV-2 infection and exposure to farming-related atmospheric pollutants worsens the effect of SARS-CoV-2 on mortality. Our objective was investigate this hypothesis by performing an ecological study in five Italian Regions (Piedmont, Lombardy, Veneto, Emilia-Romagna and Sicily) linking all-cause mortality, by province (administrative entities within regions), to atmospheric particulate matter ( $\mathrm{PM}_{2.5}$ and $\left.\mathrm{PM}_{10}\right)$ nitrous oxide $\left(\mathrm{N}_{2} \mathrm{O}\right)$, ammonia $\left(\mathrm{NH}_{3}\right)$ and methane $\left(\mathrm{CH}_{4}\right)$ mainly produced by agricultural activities. Study outcome was change in all-cause mortality during March-April 2020, compared to March-April 2015-2019 (period) as assessed by mortality rate ratios (MRRs) estimated using multivariate negative binomial regression models that adjusted for air temperature, humidity and population density. The MRR for the interaction of period with $\mathrm{NH}_{3}$ exposure, considering all pollutants together was 1.133 , equivalent to a $13.3 \%$ 
Keywords: particulate matter; SARS-CoV-2; mortality; pollution; ammonia; methane;

nitrous oxide; farming; livestock

\section{Introduction}

According to the World Health Organization, on March 31, 2021, worldwide there were 128,540,982 confirmed cases of SARS-CoV-2 infection (COVID-19) and 2,808,308 deaths (2.18\% of confirmed cases) [1]. The corresponding figures for Italy were 3,584,899 confirmed cases and 109,346 (3.5\%) deaths [1]. These are likely to be underestimates [2].

Several studies have investigated effects of environmental and meteorological factors on the dissemination and severity of viral respiratory infections [3-6]. A 2018 paper provided evidence that air pollution from coal burning had exacerbated the "Spanish flu" pandemic of 1918 [7]. Although most COVID-19 patients develop mild or no symptoms, more severe and life-threatening symptoms such as pneumonia (often leading to acute respiratory distress syndrome), vascular inflammation and thrombosis, myocarditis, and cardiac arrhythmia, also occur, typically associated with excessive inflammation and cytokine storm [8].

Long-term and short-term exposure to atmospheric particulate matter $\leq 10 \mu \mathrm{m}$ $\left(\mathrm{PM}_{10}\right)$ and $\leq 2.5 \mu \mathrm{m}\left(\mathrm{PM}_{2.5}\right)$ have been linked to respiratory and cardiovascular events [9]. A recent US study found that an increase of just $1 \mu \mathrm{g} / \mathrm{m}^{3}$ in long-term exposure to $\mathrm{PM}_{2.5}$ was associated with an $8 \%$ increase in the COVID-19 death rate [10]. Studies in Italy have identified associations between COVID-19 and COVID-19-related death and exposure to $\mathrm{PM}_{10}$ and $\mathrm{PM}_{2.5}$ [11-14]; while tropospheric nitrogen dioxide (NO2) in northern Italy was associated with levels of SARS-CoV-2 infection [15]. The COVID-19 pandemic in Italy started in the Po Valley of northern Italy - one of the most polluted areas in the world [16] - where intensive livestock rearing and heavy use of fertilizers make major contributions to atmospheric pollution [17]. In December 2019 in the Po Valley Regions of Lombardy, Piedmont, Emilia-Romagna and Veneto, there were, respectively, 1,543,639, 824,801, 627,627 and 824,112 cattle, and 3,984,633, 1,121,723, $1,377,527$, and 717,557 pigs. In comparison, the island Region of Sicily had 387,619 cattle and 45,152 pigs [18]. As regards nitrogen fertilizer use, the 2019 figures (tonne $/ \mathrm{km}^{2} /$ year) were 12.92 in Lombardy, 8.27 in Piedmont, 18.64 in Veneto, and 19.50 in EmiliaRomagna, compared to 5.20 in Sicily [18].

Agricultural activity produces $\mathrm{NH}_{3}, \mathrm{CH}_{4}$ and $\mathrm{N}_{2} \mathrm{O}$, and also $\mathrm{PM}_{10}$ and $\mathrm{PM}_{2.5}$ [19-21]. In Italy, agriculture is the main source of $\mathrm{NH}_{3}$ emissions, with an estimated 362.18 kilotonnes/year, accounting for 94.3\% of the total [19]. In Lombardy in 2017 (latest year for which figures are available) the proportion of $\mathrm{NH}_{3}$ emissions from agriculture varied by province (68-99\%), as did the proportions of $\mathrm{CH}_{4}$ and $\mathrm{N}_{2} \mathrm{O}$ emissions $(7-87 \%$ and $27-$ $94 \%$, respectively) [22].

Analysis of all-cause mortality data indicates that COVID-19-related deaths are underestimated [2;23]. A study that analysed 22 countries reported that in Italy COVID- 
19-related deaths were underestimated by $30 \%$ with similar underestimates in several other countries [24]. For this reason all-cause mortality is the epidemiologic indicator of choice for assessing the mortality impact of COVID-19 [2;25-26] from which excess deaths can be estimated as proxy of COVID-19 mortality [25].

We hypothesized that long-term exposure to farming-related air pollutants might predispose to increased risk of COVID-19-related death. To do this we performed the preliminary investigation presented in this work: this was an ecological study, firstly to find out whether the results justified additional analytic studies. Secondly because there was a possibility of identifying modifiable risk factors to limit the effect of the COVID-19 on mortality.

\section{Materials and Methods}

\subsection{Study Design}

We conducted an ecological study to investigate whether interaction between SARS-CoV-2 infection and exposure to farming-related air pollutants worsened the effect of SARS-CoV-2 on mortality at the level of the Provinces (administrative entities within Regions) in the Italian Regions of Lombardy, Emilia-Romagna, Piedmont, Veneto, and Sicily. We investigated the period of the first COVID-19 wave (March-April 2020) in comparison with the same two-month period in the years 2015 to 2019. Mortality differences between these two periods are a good proxy for mortality due to COVID-19.

\subsection{Pollutant Exposure}

We assessed atmospheric $\mathrm{PM}_{2.5}, \mathrm{PM}_{10}, \mathrm{~N}_{2} \mathrm{O}, \mathrm{NH}_{3}, \mathrm{CH}_{4}$ and $\mathrm{NO}_{2}$. The first five were included because they are linked to farming; $\mathrm{NO}_{2}$ was included because it could be a confounder or effect modifier. Atmospheric $\mathrm{PM}_{2.5}, \mathrm{PM}_{10}$ and $\mathrm{NO}_{2}$ levels are measured by monitoring stations and the data archived by Regional Environmental Protection Agencies (ARPAs) [27-31]. We accessed ARPA data from the monitoring stations in the chief towns of each Province and used them as proxies for exposure of the entire provincial populations. We averaged daily concentrations of over 2019 to arrive at estimates of long-term exposure. However for $\mathrm{PM}_{10}$ and $\mathrm{NO}_{2}$ we had use the latest available data (2015) for one province, and used the data from an adjacent province in another province. We did not use 2020 data, as they could have biased estimates because of changes in pollutant levels caused by lockdown [32;33].

$\mathrm{NH}_{3}$ concentrations are monitored by too few stations to be representative of the areas being studied; and levels of $\mathrm{CH}_{4}$ and $\mathrm{N}_{2} \mathrm{O}$ are not measured routinely. We therefore estimated levels of atmospheric $\mathrm{NH}_{3}, \mathrm{CH}_{4}$ and $\mathrm{N}_{2} \mathrm{O}$, again at the level of the provinces. These estimates were derived from estimates produced by the ARPAs [22;31].

ARPAs estimate $\mathrm{NH}_{3}$ emissions for each province and for each known source (e.g. pigs) by multiplying the average number pigs per year present in the province by an estimate of the average production by each animal (as $\mathrm{kg} \mathrm{NH}_{3} /$ animal/year). A similar method is applied to each type of livestock present, and also other $\mathrm{NH}_{3}$ sources (e.g. fertilizer use). Total $\mathrm{NH}_{3}$ emissions are obtained by summing estimate emissions from all known sources. Similar methods are used to estimate emissions of $\mathrm{CH}_{4}$ and $\mathrm{N}_{2} \mathrm{O}$.

We next derived provincial exposure indices from the ARPA estimates by dividing the total estimated quantities of emissions (tonne/year) by the area $\left(\mathrm{km}^{2}\right)$ of the province, thereby taking account of variations in province area. We used data for the latest available year as proxy for long-term exposure: 2017 for Lombardy and Emilia-Romagna 
(except for one province for which data were for 2016), 2015 for Piedmont and Veneto, and 2012 for Sicily.

Backes et al. [34] showed that the atmospheric concentration patterns of $\mathrm{NH}_{3}$ are in line with $\mathrm{NH}_{3}$ emission patterns, indicating the provincial exposure indices are acceptable indicators of atmospheric $\mathrm{NH}_{3}$. To further investigate provincial exposure indices as indicators of atmospheric pollution levels we assessed correlations (Pearson's r) between $\mathrm{NH}_{3}$ emissions and cattle numbers, pig numbers and fertilizer use per $\mathrm{km}^{2}$ by region. We could only compare data at the regional level because of the unavailability of data on numbers of pigs and cattle and nitrogen fertilizer use at the provincial level,

\subsection{Meteorological Variables}

We hypothesized that temperature influenced COVID-19 rates over the short-term and so might have an effect on mortality. We therefore used temperature and humidity, as measured by ARPA monitoring stations in the main town of each province, as proxies for the average temperature and average relative humidity in each province, in March and April in 2020, and also in March-April 2019.

\subsection{Additional covariates}

Educational level is a potential risk factor for SARS-CoV2 infection and death [35]. We therefore downloaded provincial data on educational level from ISTAT [36] (as proportion of people who continued schooling after 14 years of age) and added these as covariates to the models. Social deprivation is also linked to SARS-CoV-2 infection and death [37]. However social deprivation indices at the provincial level were not available so we assumed that educational level was an approximate proxy for social deprivation. Income is also a component of social deprivation but was not available at provincial level so we accessed regional level data from ISTAT [40] and assessed correlations (Pearson's r) with $\mathrm{NH}_{3}$ by regions to provide indications as to the possible effects of income on our findings.

High body mass index (BMI) and diabetes are recognized as major risk factors for SARS-CoV2 death [38;39] and could bias estimates of links between farming-related pollutants and SARS-CoV-2 mortality. Provincial level data were unavailable, so we accessed regional level data from ISTAT [40] and assessed correlations (Pearson's r) with $\mathrm{NH}_{3}$ to provide indications as to the possible effects of BMI and diabetes on our findings.

Variation in lockdown periods across provinces could also bias the results of a study like this. However in Italy during the first COVID-19 wave, days of lockdown were closely similar throughout the country. Similarly, regulations to limit contagion (mask-wearing, social distancing) applied to the whole country during the two-month study period.

\subsection{Outcome}

All-cause daily mortality data, provided by the Italian National Statistics Institute (ISTAT) [41], was primary study outcome. Mortality data are available by municipality (administrative entities within provinces). We calculated total mortality by province, for March-April 2020, as the sum of the daily death counts in all the municipalities in each province. We also estimated average mortality in March-April of 2015-2019, as the 
average, over the five years, of the sum of daily death counts in all the municipalities of each province.

\subsection{Statistical Methods}

We first sought correlations (Pearson's $\mathrm{r}$ ) between levels of the atmospheric pollutants being studied $\left(\mathrm{PM}_{2.5}, \mathrm{PM}_{10}, \mathrm{~N}_{2} \mathrm{O}, \mathrm{NH}_{3}, \mathrm{CH}_{4}\right.$ and $\left.\mathrm{NO}_{2}\right)$. We next analyzed associations between changes in total mortality from March-April 2015-2019 to 2020 and atmospheric pollutant levels, humidity, temperature, and population density (study covariates). To do this we used negative binomial regression models, that included a population size offset, and which estimated mortality rate ratios (MRRs) in relation to study covariates. MRR is the ratio of the mortality rate for a specific value of a covariate relative to reference. Thus, for the covariate "period" MRR is mortality in March-April 2020 relative to mortality in March-April in 2015-2019, and is a good proxy for the increase in mortality due to COVID-19. We were particularly interested in MRRs for the interaction between period and the other covariates (mainly pollutant levels) as these are an estimate of the mortality associated with the pollutant over and above that due to COVID-19 alone.

We first ran basic models that included period, one covariate, and an interaction term between period and covariate. We next ran complete models that included all covariates, and all interaction terms between period and covariates.

Information on $\mathrm{PM}_{10}$ levels was available for all provinces, while $\mathrm{PM}_{2.5}$ data were unavailable for six provinces. We therefore ran two sets of models, one that included all 45 provinces but excluded $\mathrm{PM}_{2.5}$, and another that included $\mathrm{PM}_{2.5}$ and the 39 provinces for which $\mathrm{PM}_{2.5}$ was available. The R statistical package [42], version 4.0.2 was used to perform the analyses.

\section{Results}

Supplementary Table S1 lists the provinces included in the study, together with their populations, population densities. Compared to mortality in March-April 20152019, mortality in March-April 2020 varied from a 1.8\% decrease in Agrigento Province (Sicily) to a $364.3 \%$ increase in Bergamo (Lombardy). Mean values of atmospheric PM10, $\mathrm{PM}_{2.5}$ and $\mathrm{NO}_{2}$ across provinces were $26.01,17.58$ and $25.23 \mu \mathrm{g} / \mathrm{m}^{3}$ respectively; the $\mathrm{PM}_{10}$ ranged from 14.0 (Verbano-Cusio-Ossola, Piedmont) to $35.2 \mu \mathrm{g} / \mathrm{m}^{3}$ (Cremona, Lombardy), the $\mathrm{PM}_{2.5}$ ranged from 8.0 (Enna, Sicily) to $26.1 \mu \mathrm{g} / \mathrm{m}^{3}$ (Cremona, Lombardy), and the $\mathrm{NO}_{2}$ ranged from 4.0 (Agrigento, Sicily) to $45.7 \mu \mathrm{g} / \mathrm{m}^{3}$ (Monza Brianza, Lombardy).

As regards emissions, mean across-province exposure index estimates for $\mathrm{NH}_{3}, \mathrm{CH}_{4}$ and $\mathrm{N}_{2} \mathrm{O}$ were $2.22,9.76$, and 0.36 tonne $/ \mathrm{km}^{2} /$ year, respectively. The $\mathrm{NH}_{3}$ exposure index ranged from 0.12 (Verbano-Cusio-Ossola, Piedmont) to 10.3 tonne $/ \mathrm{km}^{2} /$ year (Cremona, Lombardy); the $\mathrm{CH}_{4}$ index ranged from 1.47 (Sondrio, Lombardy) to 33.17 tonne/ $\mathrm{km}^{2} /$ year (Milan, Lombardy), and the $\mathrm{N}_{2} \mathrm{O}$ index ranged from 0.06 (VerbanoCusio-Ossola, Piedmont) to 1.12 tonne/ $\mathrm{km}^{2} /$ year (Cremona, Lombardy).

Table 1 shows Pearson correlation coefficients for atmospheric pollutants $\mathrm{PM}_{10}$, $\mathrm{PM}_{2.5}, \mathrm{NO}_{2}, \mathrm{NH}_{3}, \mathrm{CH}_{4}$, and $\mathrm{N}_{2} \mathrm{O}$. 
Table 1. Pearson's correlation coefficients between atmospheric pollutants

\begin{tabular}{ccccccc}
\hline Air pollutant & $\mathbf{P M}_{10}$ & $\mathbf{P M}_{2.5}$ & $\mathbf{N O}_{2}$ & $\mathbf{N H}_{3}$ & $\mathbf{C H}_{4}$ & $\mathbf{N}_{2} \mathbf{O}$ \\
\hline $\mathrm{PM}_{10}$ & 1.00 & 0.84 & 0.52 & 0.51 & 0.51 & 0.57 \\
$\mathrm{PM}_{2.5}$ & 0.84 & 1.00 & 0.60 & 0.46 & 0.48 & 0.61 \\
$\mathrm{NO}_{2}$ & 0.52 & 0.60 & 1.00 & 0.27 & 0.64 & 0.37 \\
$\mathrm{NH}_{3}$ & 0.51 & 0.46 & 0.27 & 1.00 & 0.68 & 0.92 \\
$\mathrm{CH}_{4}$ & 0.51 & 0.48 & 0.64 & 0.68 & 1.00 & 0.80 \\
$\mathrm{~N}_{2} \mathrm{O}$ & 0.57 & 0.61 & 0.37 & 0.92 & 0.80 & 1.00 \\
\hline
\end{tabular}

Table 2 presents modelling results for all 45 provinces included in the study: the MRRs represent percentage increases in overall death rate in relation to increments of 1 $\mu \mathrm{g} / \mathrm{m}^{3}$ in $\mathrm{PM}_{10}$, and $\mathrm{NO}_{2}, 1$ tonne $/ \mathrm{km}^{2}$ increments in $\mathrm{NH}_{3}, \mathrm{CH}_{4}$ and $\mathrm{N}_{2} \mathrm{O}$, a $1^{\circ} \mathrm{C}$ increment in atmospheric temperature, a $1 \%$ increment in relative humidity, a one unit increase in population density, or in people who continued schooling after 14 years of age compared to those who attended only up to 14 years.

Table 2. Mortality rate ratios (MRRs)* with $95 \%$ confidence intervals (CI) for all 45 Italian provinces included in the study.

\begin{tabular}{|c|c|c|}
\hline & Basic model ${ }^{\S}$ & Complete model ${ }^{\ddagger}$ \\
\hline $\mathrm{PM}_{10}$ & $0.997(0.981-1.013)$ & $1.003(0.985-1.021)$ \\
\hline $\mathrm{PM}_{10}$ and period interaction & $1.027(1.004-1.050)$ & $0.995(0.970-1.020)$ \\
\hline $\mathrm{NO}_{2}$ & $0.996(0.986-1.006)$ & $1.000(0.987-1.013)$ \\
\hline $\mathrm{NO}_{2}$ and period interaction & $1.025(1.010-1.040)$ & $1.017(0.999-1.037)$ \\
\hline $\mathrm{NH}_{3}$ & $0.992(0.958-1.029)$ & $0.997(0.909-1.088)$ \\
\hline $\mathrm{NH}_{3}$ and period interaction & $1.094(1.040-1.151)$ & $1.133(1.003-1.281)$ \\
\hline $\mathrm{N}_{2} \mathrm{O}$ & $0.882(0.623-1.266)$ & $0.721(0.249-2.91)$ \\
\hline $\mathrm{N}_{2} \mathrm{O}$ and period interaction & $2.195(1.340-3.595)$ & $0.243(0.056-1.128)$ \\
\hline $\mathrm{CH}_{4}$ & $0.994(0.982-1.007)$ & $1.012(0.984-1.041)$ \\
\hline $\mathrm{CH}_{4}$ and period interaction & $1.032(1.015-1.051)$ & $1.043(1.001-1.087)$ \\
\hline Temperature & $0.983(0.901-1.072)$ & $0.996(0.928-1.070)$ \\
\hline Temperature and period interaction & $0.961(0.839-1.102)$ & $0.980(0.881-1.090)$ \\
\hline Humidity & $1.003(0.990-1.016)$ & $1.002(0.989-1.015)$ \\
\hline
\end{tabular}


Humidity and period interaction

Population density

Population density and period interaction

Education

Education and period interaction

Period (2020 vs. 2015-2019)
$0.995(0.978-1.012)$

$0.987(0.970-1.003)$

$1.000(0.999-1.001)$

1.000 (0.999-1.001)

$1.000(0.999-1.001)$

$1.000(0.999-1.001)$

$0.991(0.965-1.019)$

1.004 (0.973-1.035)

$1.022(0.983-1.063)$

$0.992(0.950-1.036)$

1.739 (1.526-1.983)

* MMRs are percentage increases in overall death rate associated with: $1 \mu \mathrm{g} / \mathrm{m}^{3}$ increase in atmospheric PM10; $1 \mu \mathrm{g} / \mathrm{m}^{3}$ increase in atmospheric $\mathrm{NO}_{2} ; 1$ tonne/year $/ \mathrm{km}^{2}$ increases in emissions of $\mathrm{NH}_{3}, \mathrm{CH}_{4}$ or $\mathrm{N}_{2} \mathrm{O} ; 1^{\circ} \mathrm{C}$ increase in atmospheric temperature, $1 \%$ increase in relative humidity, one unit increase in population density, or in people who continued schooling after 14 years of age compared to those who attended only up to 14 years.

$\S$ Basic models include only period, a single covariate and its interaction with period. $\ddagger$ Complete models include all covariates together with their interactions with period.

The basic regression models identified significantly increased MMRs for interactions between period and: PM10 (MRR: 1.027; 95\%CI: 1.004-1.050), $\mathrm{NO}_{2}$ (MRR: 1.025; 95\%CI: 1.010-1.040), $\mathrm{NH}_{3}$ (MRR: 1.094; 95\%CI: 1.040-1.151), $\mathrm{N}_{2} \mathrm{O}$ (MRR: 2.195; 95\%CI: 1.340-3.595) and $\mathrm{CH}_{4}$ (MRR: 1.032; 95\%CI: 1.015-1.051) indicating that high levels of these pollutants were significantly linked to an increase in total mortality over and above that due to period (proxy for presence of COVID-19). None of the individual covariates was significantly associated with MRR.

In the complete models, MRRs for the interaction between $\mathrm{CH}_{4}$ and period (MRR: 1.043; 95\%CI: 1.001-1.087) and also for the interaction between $\mathrm{NH}_{3}$ and period (MRR: 1.133; 95\%CI: 1.003-1.281) remained significant, indicating that an increase of 1 tonne $/ \mathrm{km}^{2} /$ year in $\mathrm{NH}_{3}$ emissions was significantly associated with a $13.3 \%$ increase in all-cause death over and above that associated with period (proxy for COVID-19). MRRs for interaction of period with $\mathrm{PM}_{10}, \mathrm{~N}_{2} \mathrm{O}$ and $\mathrm{NO}_{2}$ all reduced, compared to the basic model, and became non-significant.

Table 3 shows results for the 39 provinces for which $\mathrm{PM}_{2.5}$ data were available. The MRRs were similar to those obtained for all 45 provinces, except that in the basic model, MRR for interaction between period and $\mathrm{PM}_{2.5}$ was significant, but for $\mathrm{PM}_{10}$ was not. As regards the complete models, only the MRR for interaction between period and $\mathrm{NH}_{3}$ was significant $(1.145$; 95\%CI: $1.006-1.305)$ corresponding to a $14.5 \%$ increase (over and above that for period alone) in mortality for each tonne $/ \mathrm{km}^{2} /$ year increase in $\mathrm{NH}_{3}$ emissions.

Correlation analysis found the following correlations: 0.92 between provincial exposure index for $\mathrm{NH}_{3}$ and number of pigs per $\mathrm{km}^{2} ; 0.96$ between provincial exposure index for $\mathrm{NH}_{3}$ and number of cattle per $\mathrm{km}^{2} ; 0.53$ between the provincial exposure index for $\mathrm{NH}_{3}$ and number of cattle per $\mathrm{km}^{2}$. In addition correlations were: -0.87 between BMI and the provincial exposure index for $\mathrm{NH}_{3}$; and -0.77 between diabetes and the provincial exposure index for $\mathrm{NH}_{3}$; and 0.42 between yearly average income and the regional exposure index for $\mathrm{NH}_{3}$. These findings suggest that emission levels are a reasonable surrogate for atmospheric levels. Given the strength of the association of 
COVID-related mortality increase $(13.3 \%)$ due to $\mathrm{NH}_{3}$, it is unlikely that BMI, diabetes and income would have had biased this association.

Table 3. Mortality rate ratios (MRRs)* with 95\% confidence intervals (CI). Analyses restricted to the 39 Italian provinces for whichPM 2.5 data were available.

Variable

MRR (95\%CI)

\begin{tabular}{|c|c|c|}
\hline & \multirow{2}{*}{ Basic models } & \multirow{2}{*}{ Complete model^ $^{\wedge}$} \\
\hline & & \\
\hline $\mathrm{PM}_{10}$ & $0.996(0.979-1.013)$ & $1.006(0.980-1.033)$ \\
\hline $\mathrm{PM}_{10}$ and period interaction & $1.021(0.997-1.045)$ & $0.989(0.953-1.026)$ \\
\hline $\mathrm{PM}_{2.5}$ & $0.994(0.972-1.015)$ & $0.997(0.959-1.037)$ \\
\hline $\mathrm{PM}_{2.5}$ and period interaction & $1.034(1.003-1.066)$ & $1.011(0.957-1.068)$ \\
\hline $\mathrm{NO}_{2}$ & $0.994(0.983-1.005)$ & $0.998(0.983-1.013)$ \\
\hline $\mathrm{NO}_{2}$ and period interaction & $1.021(1.005-1.039)$ & $1.018(0.996-1.040)$ \\
\hline $\mathrm{NH}_{3}$ & $0.991(0.956-1.029)$ & $0.996(0.900-1.092)$ \\
\hline $\mathrm{NH}_{3}$ and period interaction & $1.082(1.027-1.139)$ & $1.145(1.006-1.305)$ \\
\hline $\mathrm{N}_{2} \mathrm{O}$ & $0.866(0.606-1.255)$ & $0.724(0.239-2.339)$ \\
\hline $\mathrm{N}_{2} \mathrm{O}$ and period interaction & $1.943(1.174-3.212)$ & $0.238(0.049-1.125)$ \\
\hline $\mathrm{CH}_{4}$ & $0.994(0.981-1.007)$ & $1.011(0.983-1.042)$ \\
\hline $\mathrm{CH}_{4}$ and period interaction & $1.028(1.009-1.046)$ & $1.039(0.995-1.084)$ \\
\hline Temperature & $0.980(0.883-1.087)$ & $1.003(0.916-1.097)$ \\
\hline Temperature and period interaction & $1.010(0.858-1.187)$ & $0.980(0.853-1.128)$ \\
\hline Humidity & $1.005(0.989-1.022)$ & $1.004(0.990-1.019)$ \\
\hline Humidity and period interaction & $1.003(0.983-1.023)$ & $0.972(0.972-1.008)$ \\
\hline Population density & $1.000(0.999-1.001)$ & $1.000(0.999-1.001)$ \\
\hline Population density and period interaction & $1.000(0.999-1.001)$ & $1.000(0.999-1.001)$ \\
\hline Education & $0.986(0.957-1.016)$ & $1.003(0.968-1.039)$ \\
\hline Education and period interaction & $1.004(0.962-1.048)$ & $0.990(0.943-1.039)$ \\
\hline Period (2020 year vs. 2015-2019) & $1.846(1.611-2.116)$ & $4.246(0.16-112.134)$ \\
\hline
\end{tabular}


* MMRs: percentage increases in overall death rate associated with: $1 \mu \mathrm{g} / \mathrm{m}^{3}$ increase in atmospheric particulate matter $\left(\mathrm{PM}_{2.5}\right.$ or $\left.\mathrm{PM} 10\right) ; 1 \mu \mathrm{g} / \mathrm{m}^{3}$ increase in atmospheric $\mathrm{NO}_{2} ; 1$ tonne $/ \mathrm{km}^{2}$ year increases $\mathrm{NH}_{3}, \mathrm{CH}_{4}$ or $\mathrm{N}_{2} \mathrm{O}$ emissions; $1^{\circ} \mathrm{C}$ increase in atmospheric temperature, $1 \%$ increase in relative humidity, one unit increase in population density, or people who continued schooling after 14 years of age compared to those who attended only up to 14 years. $\S$ Basic models include only period, a single covariate and its interaction with period.^ Complete models include all covariates and their interactions with period.

\section{Discussion}

Using basic models, which excluded most covariates, we found that higher $\mathrm{NH}_{3}$, $\mathrm{CH}_{4}$, and $\mathrm{N}_{2} \mathrm{O}$ emissions - whose major source is agriculture - were associated with allcause mortality increases in 2020,compared to previous years, over and above those due to period (proxy for COVID-19-related mortality). Higher PM10, $\mathrm{PM}_{2.5}$ and $\mathrm{NO}_{2}$ were also associated with all-cause mortality increases over and above those due to period.

Using complete models, that included all other studied pollutants as covariates, higher $\mathrm{NH}_{3}$ levels remained associated with a significant all-cause mortality increase: a one tonne/ $/ \mathrm{km}^{2}$ increase in $\mathrm{NH}_{3}$ was associated with a $13.3 \%$ increase in mortality over and above that due to period. High $\mathrm{CH}_{4}$ levels also remained associated with a significant all-cause mortality increase in the complete model that includes all provinces, but not in the complete model that only included provinces for which for which PM2.5 data were available.

The fact that interactions of period with $\mathrm{N}_{2} \mathrm{O}, \mathrm{PM}_{10}, \mathrm{PM}_{2.5}$ (and to some extent $\mathrm{CH}_{4}$ ) were not associated with excess mortality in the complete models is likely due to the fact that levels of these pollutants correlated highly with each other.

A major study assumption was that the provincial exposure index based on pollutant emissions is a good proxy for levels of that pollutant in the atmosphere. This assumption in supported by the study of Backes et al. [34] which showed that atmospheric concentration patterns of $\mathrm{NH}_{3}$ are in line with $\mathrm{NH}_{3}$ emission patterns. To further investigate provincial exposure indices as indicators of atmospheric pollution levels we assessed correlations (Pearson's $\mathrm{r}$ ) between $\mathrm{NH}_{3}$ emissions and cattle numbers, pig numbers and nitrogen fertilizer use, per $\mathrm{km}^{2}$, by region (provincial data unavailable): we found high or good correlations (0.96, 0.92 and 0.53 , respectively) indicating that estimated emissions are consistent with the emission sources present, and suggesting that these estimated emissions (standardized by area size) are a reasonable proxy for atmospheric $\mathrm{NH}_{3}$ concentrations.

It is known that BMI and diabetes are major risk factors for COVID-19 infection and death. However provincial data for BMI and diabetes were not available and could not be included in our models as covariates. We indirectly assessed whether the association between farming-related pollutants and SARS-CoV-2 mortality were biased by BMI, diabetes and income by estimating correlations between $\mathrm{BMI}$ and $\mathrm{NH}_{3}$, between diabetes and $\mathrm{NH}_{3}$, and between income $\mathrm{NH}_{3}$ at the regional level. As noted, given the strength of the association of COVID-related mortality increase $(13.3 \%)$ due to $\mathrm{NH}_{3}$, it is unlikely that BMI, diabetes and income would exerted a major bias on this association. Any influence of population density and educational level on associations was taken account of by entering these as covariates in the models.

To our knowledge this is the first study to investigate relationships between farming-related atmospheric pollution and COVID-19-related mortality. However, a 2020 study conducted in Italy found that the number of SARS-CoV-2 infections per unit population depended on the type of rural landscape [43]. The study classified rural 
landscapes into: (A) urban and periurban with high intensity agriculture; (B) high intensity agriculture; (C) medium intensity agriculture (hilly areas), (D) low intensity agriculture (high hills and mountains). They found that areas of less intense agriculture (C, D) had fewer COVID-19 cases (per 10,000 inhabitants) than areas of intensive agriculture (A and B). Notwithstanding the markedly different methodologies, both our study and [43] identified intensive farming as a risk factor for COVID-19.

Similarly, the 2020 Lancet Countdown report highlighted a link between SARSCoV-2 infection, environmental degradation and climate change; and identified agriculture one of the main sources of pollutant emissions [44].

Other studies have reported associations between exposure to livestock farming and respiratory diseases. Thus, a Netherlands study found that people living in high livestock density areas had a significantly higher prevalence of pneumonia than those living in low density areas [45]. A German study [46] found that people exposed to higher levels of $\mathrm{NH}_{3}$ had poorer pulmonary health and were more likely to be sensitized to ubiquitous allergens, than persons with lower $\mathrm{NH}_{3}$ exposure. A study performed in an agricultural region of Washington State (US) found that industrial-scale animal feeding operations were associated with higher daily outdoor $\mathrm{NH}_{3}$ levels, and that forced expiratory volume in 1 second was lower with each interquartile increase in the previous day's $\mathrm{NH}_{3}$ exposure; however no associations with asthma symptoms were observed [47]. The European Academy of Allergy and Clinical Immunology position paper [48] has highlighted that increased risks of developing the respiratory diseases and allergies are associated with animal farming, and emphasized the need to protect workers from such risks.

The data provided by the above cited-studies [45-48] suggests that a link between excess COVID-19-related mortality and farming-related atmospheric pollutants is biologically plausible. The specific association we found between COVID-19-related mortality and $\mathrm{NH}_{3}$ might be explained by the hypothesis that atmospheric $\mathrm{NH}_{3}$ leads to the formation of alkaline aerosol which triggers a conformation change in the SARSCoV-2 spike that facilitates fusion of the viral envelope with the plasma membrane of target cells [49]. It is noteworthy that clusters of SARS-CoV-2 infection have been reported in association with slaughterhouses [50] which are known to have elevated levels of $\mathrm{NH}_{3}$ [51].

We used change in all-cause total mortality in 2020 as a proxy for SARS-CoV-2 mortality, and to our knowledge our study is the first to do this. A strength of this approach is that it avoids loss of deaths due to underreporting of SARS-CoV-2 mortality [25]. However the pandemic may have stressed health resources so that more people than usual may have died from non-COVID-19 causes, somewhat inflating all-cause mortality. The main limitations of the study are that, for atmospheric pollutants that were measured, we used levels measured at the monitoring station in the chief town of the province as proxy for exposure of the entire provincial population. In addition, for the atmospheric pollutants $\mathrm{NH}_{3} \mathrm{CH}_{4}$ and $\mathrm{N}_{2} \mathrm{O}$, measured levels were not available and we used estimated emissions at the provincial level obtained from the regional environmental protection agencies, as proxies for exposure of the provincial populations.

\section{Conclusions}

Although the study was ecological, and could not identify causal links between farming-related atmospheric pollutants and COVID-19 mortality, it suggests that studies to further address this issue would be worthwhile, particularly since other data also 
indicate links between farming-derived pollutants and worsened outcomes of SARS$\mathrm{CoV}-2$ and other viral infections.

The agricultural sector is responsible for most $\mathrm{NH}_{3}$ emissions [19]. In view of the continuing severity of the SARS-CoV-2 pandemic it is important to implement measures that can speedily reduce $\mathrm{NH}_{3}$ emissions from agriculture, for example by covering tanks containing slurry [53]. However over the medium term structural changes are required to reduce farming-related pollution. Consumption of meat, particularly red meat, is recognized as a threat to human health and wellbeing in part because of the effect of livestock rearing on the environment, as documented the 2020 Lancet Countdown Report [44]. The desire to consume meat encourages the use of intensive farming resulting in increase emission of farming-related pollutants. As urged by the Lancet Report [44] and by Agnoletti et al. [43] we need to move towards more sustainable agriculture with reduced livestock raising. Finally we note that intensive agriculture is also a major cause of biodiversity loss worldwide, which has been implicated in the emergence of SARS-CoV-2 and other viruses [44;52].

Author Contributions: Conceptualization, P.C. and W.M.; Methodology, PC; Validation, A.A., G.C., A.B., M.B., P.T., M.C.D., S.R., S.S., G.T., R.B., V.K., F.T., C.M.M, V.R., C.C., G.L., A.C., A.R., C.V., C.DM.; Formal Analysis, P.C., V.P., M.Z.; Investigation, P.C., A.B., M.B., A.C.; Writing Original Draft Preparation, P.C., W.M.; Writing - Review \& Editing, all authors; Supervision, P.C., W.M.; Project Administration, P.C. All authors have read and agreed to the published version of the manuscript.

Funding: This research received no external funding

Informed Consent Statement: This study used only aggregated data available on websites accessible to the public.

Data Availability Statement: This study we used only aggregated data available on web-sites accessible to the public.

Acknowledgments: The authors thank Don Ward for help with the English and for a critical reading of the manuscript.

Conflicts of Interest: The authors declare no conflicts of interest.

\section{References}

1. WHO Coronavirus Disease (COVID-19): https://covid19.who.int (archived on 31 March 2021).

2. Raleigh, V.S. UK's record on pandemic deaths. BMJ 2020, 370:m3348. doi: 10.1136/bmj.m3348. PMID: 32887679

3. Rader, B., Scarpino, S.V., Nande, A., Hill, A.L., Adlam, B., Reiner, R.C., Pigott, D.M., Gutierrez, B., Zarebski, A.E., Shrestha, M. et al. Crowding and the shape of COVID-19 epidemics. Nat Med 2020, 26, 1829-1834. doi: 10.1038/s41591-020-1104-0.

4. Chen, G., Zhang, W., Li, S., Williams, G., Liu, C., Morgan, G.G., Jaakkola, J.J.K., Guo, Y. Is short-term exposure to ambient fine particles associated with measles incidence in China? A multi-city study. Environ Res. 2017, 156, 306-311. doi: 10.1016/j.envres.2017.03.046

5. Cui, Y., Zhang, Z.F., Froines, J., Zhao, J., Wang, H., Yu, S.Z., Detels, R. Air pollution and case fatality of SARS in the People's Republic of China: an ecologic study. Environ Health 2003, 2(1):15. doi 10.1186/1476-069X-2-15

6. Contiero, P., Boffi, R., Tagliabue, G., Scaburri, A., Tittarelli, A., Bertoldi, M., Borgini, A., Favia, I., Ruprecht, A.A., Maiorino, A. et al. A Case-Crossover Study to Investigate the Effects of Atmospheric Particulate Matter Concentrations, Season, and Air Temperature on Accident and Emergency Presentations for Cardiovascular Events in Northern Italy. Int J Environ Res Public Health 2019, 16(23), 4627. doi: 10.3390/ijerph16234627

7. Clay, K., Lewis J., Severnini, E. Pollution, Infectious Disease, and Mortality: Evidence from the 1918 Spanish Influenza Pandemic. The Journal of Economic History 2018, 1179-1209. doi:10.1017/S002205071800058X

8. Hu, B., Huang, S., Yin, L. The cytokine storm and COVID-19. J. Med. Virol. 2021, 93, 250-256 . doi: 10.1002/jmv.26232 
9. Requia, W.J., Adams, M.D., Arain, A., Papatheodorou, S., Koutrakis, P., Mahmoud, M. Global Association of Air Pollution and Cardio respiratory Diseases: A Systematic Review, Meta-Analysis, and Investigation of Modifier Variables. Am. J. Public Health 2018, 108, S123-S130 doi: 10.2105/AJPH.2017.303839

10. Wu, X., Nethery, R.C., Sabath, B.M., Braun, D., Dominici, F. Exposure to air pollution and COVID-19 mortality in the United States: A nationwide cross-sectional study. MedRxiv 2020, doi: 10.1101/2020.04.05.20054502

11. Accarino, G., Lorenzetti, S., Aloisio, G., Assessing correlations between short-term exposure to atmospheric pollutants and COVID-19 spread in all Italian territorial areas. Environ. Pollut. 2020, 15, 268(Pt A) doi: 10.1016/j.envpol.2020.115714

12. Coccia, M. How do low wind speeds and high levels of air pollution support the spread of COVID-19? Atmos. Pollut. Res. 2020, 12(1), 437-445. doi: 10.1016/j.apr.2020.10.002

13. Setti, L., Passarini, F., De Gennaro, G., Barbieri, P., Licen, S., Perrone, M.G., Piazzalunga, A., Borelli, M., Palmisani, J., Di Gilio, A. et al. Potential role of particulate matter in the spreading of COVID-19 in Northern Italy: first observational study based on initial epidemic diffusion. BMJ Open 2020, 10. doi: 10.1136/bmjopen-2020-039338

14. Coker, E.S., Cavalli, L., Fabrizi, E., Guastella, G., Lippo, E., Parisi, M.L., Pontarollo, N., Rizzati, M., Varacca, A., Vergalli, S. The Effects of Air Pollution on COVID-19 Related Mortality in Northern Italy. Environ Resource Econ 2020, 76, 611-634. doi: 10.1007/s10640-020-00486-1

15. Filippini, T., Rothman, K.J., Goffi, A., Ferrari, F., Maffeis, G., Orsini, N., Vinceti, M. Satellite-detected tropospheric nitrogen dioxide and spread of SARS-CoV-2 infection in Northern Italy. Sci Total Environ. 2020, 739. doi: 10.1016/j.scitotenv.2020.140278

16. Van Donkelaar, A., Martin, R.V., Brauer, M., Boys, B.L. Use of satellite observations for long-term exposure assessment of global concentrations of fine particulate matter. Environ. Health Perspect. 2015, 123, 135-143. doi: 10.1289/ehp.1408646

17. Emissions from agriculture and their control potentials: https://ec.europa.eu/environment/air/pdf/TSAP-AGRI20121129_v21.pdf (archived on 31 March 2021).

18. http://dati.istat.it (archived on 31 March 2021).

19. ISPRA: Emissioni di ammoniaca nell'ambiente. https://annuario.isprambiente.it/sys_ind/159 (archived on 31 March 2021).

20. Lovarelli, D., Conti, C., Finzi, A., Bacenetti, J., Guarino, M., Describing the trend of ammonia, particulate matter and nitrogen oxides: The role of livestock activities in northern Italy during Covid-19 quarantine. Environ Res. 2020,191,110048. doi: 10.1016/j.envres.2020.110048

21. Bauer, S.E., Tsigaridis, K., Miller, R. Significant atmospheric aerosol pollution caused by world food cultivation. Geophys. Res. Lett. 2016. 43, 5394-5400. doi:10.1002/2016GL068354

22. INEMAR (INventario Emissioni Aria). http://www.inemar.eu/xwiki/bin/view/Inemar/WebHome (archived on 31 March 2021).

23. Rivera, R., Rosenbaum, J.E., Quispe, W. Excess mortality in the United States during the first three months of the COVID-19 pandemic. Epidemiol Infect 2020, 148:e264. doi: 10.1017/S0950268820002617.

24. Kung S, Doppen M, Black M, et al. Underestimation of COVID-19 mortality during the pandemic. ERJ Open Res. 2021, 7, 00766-2020. doi: 10.1183/23120541.00766- 2020

25. Raleigh, V.S., Tackling UK's mortality problem: covid-19 and other causes. BMJ 2020, Jun 11,369:m2295. doi: 10.1136/bmj.m2295.

26. Saglietto, A., D'Ascenzo, F., Cavarretta, E., Frati, G., Anselmino, M., Versaci, F., Biondi-Zoccai, G, De Ferrari, G.M. Excess allcause mortality during COVID-19 outbreak: potential role of untreated cardiovascular disease. Minerva Cardioangiol. 2020, Sep 30. doi: 10.23736/S0026-4725.20.05349-9.

27. ARPA Lombardia: https://www.arpalombardia.it/Pages/Aria/Richiesta-Dati.aspx (archived on 31 March 2021).

28. ARPA Piemonte: http://www.sistemapiemonte.it/cms/privati/ambiente-e-energia/servizi/510-qualita-dell-aria-in-piemonte (archived on 31 March 2021).

29. ARPA Emilia-Romagna: https://www.arpae.it/dettaglio_generale.asp?id=2921\&idlivello=1637 (archived on 31 March 2021).

30. ARPA Veneto: https://www.arpa.veneto.it/arpavinforma/indicatori-ambientali/indicatori_ambientali/atmosfera/qualitadellaria (archived on 31 March 2021).

31. ARPA Sicilia: https://www.arpa.sicilia.it/temi-ambientali/aria/ (archived on 31 March 2021).

32. Altuwayjiri, A., Soleimanian, E., Moroni, S., Palomba, P., Borgini, A., De Marco, C., Ruprecht, A.A., Sioutas, C. The impact of stay-home policies during Coronavirus-19 pandemic on the chemical and toxicological characteristics of ambient PM2.5 in the metropolitan area of Milan, Italy. Sci Total Environ. 2020,14, 143582. doi: 10.1016/j.scitotenv.2020.143582.

33. Chauhan, A., Singh, R.P. Decline in PM2.5 concentrations over major cities around the world associated with COVID-19. Environ. Res. 2020, 187, 109634. https://doi.org/10.1016/j.envres.2020.109634.

34. Backes, A.M., Aulinger, A., Bieser, J., Matthias, V., Quante, M. Ammonia emissions in Europe, part II: How ammonia emission abatement strategies affect secondary aerosols. Atmospheric Environment 2016, 126, 153-161. doi: 10.1016/j.atmosenv.2015.11.039. 
35. Karmakar, M., Lantz, P.M., Tipirneni, R. Association of Social and Demographic Factors With COVID-19 Incidence and Death Rates in the US. JAMA Netw Open 2021 Jan 4;4(1):e2036462. doi:10.1001/jamanetworkopen.2020.36462.PMID: 33512520

36. http://dati-censimentopopolazione.istat.it/Index.aspx?DataSetCode=DICA_GRADOISTR1 (archived on 31 March 2021).

37. Hawkins, R.B., Charles, E.J., Mehaffey, J.H. Socio-economic status and COVID-19-related cases and fatalities. Public Health, 2020,189:129-134. doi: 10.1016/j.puhe.2020.09.016.

38. Bello-Chavolla, O.M., Bahena-López, J.P., Antonio-Villa, N.E., Vargas-Vázquez, A., González-Díaz, A., Márquez-Salinas, A., Fermín-Martínez, C.A., Jesús Naveja, J., Aguilar-Salinas ,C.A. Predicting mortality due to SARS-CoV-2: A mechanistic score relating obesity and diabetes to COVID-19 outcomes in Mexico. medRxiv 2020, 20072223. doi: 10.1101/2020.04.20.20072223

39. Drucker, D.J.. Diabetes, obesity, metabolism, and SARS-CoV-2 infection: the end of the beginning. Cell Metabolism 2021, 33(3), 479-498. doi: 10.1016/j.cmet.2021.01.016

40. http://dati.istat.it (archived on 31 March 2021).

41. ISTAT. Report on impact of the COVID-19 epidemic on the total mortality. https://www.istat.it/en/archivio/243805 (archived on 31 March 2021).

42. R Development Core Team. R: A Language and Environment for Statistical Computing 2007. http://www.rproject.org (archived on 31 March 2021).

43. Agnoletti, M., Manganelli, S. Piras, F. Covid-19 and rural landscape: The case of Italy. Landsc Urban Plan. 2020,204:103955. doi: 10.1016/j.landurbplan.2020.103955

44. Watts, N., Amann, M., Arnell, N., Ayeb-Karlsson, S., Beagley, J., Belesova, K., Boykoff, M., Byass, P., Cai, W., CampbellLendrum, D. et al. The 2020 report of The Lancet Countdown on health and climate change: responding to converging crises. Lancet 2020, S0140-6736(20)32290-X. doi: 10.1016/S0140-6736(20)32290

45. Baliatsas, C., Dückers, M., Smit, L., Heederik, D., Yzermans, J., Morbidity Rates in an Area with High Livestock Density: A Registry-Based Study Including Different Groups of Patients with Respiratory Health Problems. Int J Environ Res Public Health 2020, 17(5), 1591. doi: 10.3390/ijerph17051591.

46. Schulze, A., Römmelt, H., Ehrenstein, V., van Strien, R., Praml, G., Küchenhoff, H., Nowak, D., Radon, K. Effects on pulmonary health of neighboring residents $\mathrm{f}$ animal feeding operations: exposure assessed using optimized estimation technique. Arch. Environ. Occup. Health 2011, 66, 146-154. doi: 10.1080/19338244.2010.539635

47. Loftus, C., Afsharinejad, Z., Sampson, P., Vedal, S., Torres, E., Arias, G., Tchong-French, M., Karr, C. Estimated time-varying exposures to air emissions from animal feeding operations and childhood asthma. Int J Hyg Environ Health 2020, 223(1), 187198. doi: 10.1016/j.ijheh.2019.09.003.

48. Sigsgaard, T.; Basinas, I., Doekes, G., de Blay, F., Folletti, I., Heederik, D., Lipinska-Ojrzanowska, A., Nowak, D., Olivieri, M., Quirce, S., et al. Respiratory diseases and allergy in farmers working with livestock: a EAACI position paper. Clin Transl Allergy 2020, 10:29. doi: 10.1186/s13601-020-00334-x.

49. Manigrasso, M., Protano, C., Guerriero, E., Vitali, M., Avino, P. May SARS-CoV-2 Diffusion Be Favored by Alkaline Aerosols and Ammonia Emissions? Atmosphere 2020, 11, 995. doi: 10.3390/atmos11090995

50. Steinberg, J., Kennedy, E.D., Basler, C., Grant, M.P., Jacobs, J.R., Ortbahn, D., Osburn, J., Saydah, S., Tomasi, S., Clayton, J.L. COVID-19 Outbreak Among Employees at a Meat Processing Facility - South Dakota, March-April 2020. MMWR Morb Mortal Wkly Rep. 2020, 1015-1019. doi: 10.15585/mmwr.mm6931a2.

51. Donham, K.J., Cumro, D., Reynolds, S. Synergistic effects of dust and ammonia on the occupational health effects of poultry production workers. J. Agromed. 2002, 8, 57-76. doi:10.1300/J096v08n02_09

52. Baudron, F., Liégeois, F., Fixing our global agricultural system to prevent the next COVID-19. Outlook on Agriculture 2020, 49(2), 111-118. doi:10.1177/0030727020931122.

53. Zilio, M., Orzi, V., Chiodini, M.E., Riva, C.; Acutis, M.; Boccasile, G., Adani, F. Evaluation of ammonia and odour emissions from animal slurry and digestate storage in the Po Valley (Italy). Waste Manag. 2020, 103:296-304. doi: 10.1016/j.wasman.2019.12.038 
Table S1. Regions, provinces, areas, populations, included in the analysis.

\begin{tabular}{|c|c|c|c|c|}
\hline Region & Province & $\begin{array}{l}\text { Area } \\
\left(\mathbf{k m}^{2}\right)\end{array}$ & Population & $\begin{array}{l}\text { Population } \\
\text { density }\left(\mathbf{k m}^{-2}\right)\end{array}$ \\
\hline Piemonte & Alessandria & 3558.8 & 420017 & 118.0 \\
\hline Piemonte & Asti & 1510.1 & 214342 & 141.9 \\
\hline Piemonte & Biella & 913.2 & 174718 & 191.3 \\
\hline Piemonte & Cuneo & 6905.0 & 586814 & 84.9 \\
\hline Piemonte & Novara & 1340.2 & 369018 & 275.0 \\
\hline Piemonte & Torino & 6827.0 & 2256108 & 330.4 \\
\hline Piemonte & Verbano-Cusio-Ossola & 2260.9 & 157782 & 69.7 \\
\hline Piemonte & Vercelli & 2081.6 & 170298 & 81.8 \\
\hline Lombardy & Bergamo & 2754.9 & 1112187 & 400.0 \\
\hline Lombardy & Brescia & 4785.6 & 1265954 & 264.5 \\
\hline Lombardy & Como & 1279.0 & 599204 & 468.5 \\
\hline Lombardy & Cremona & 1770.5 & 358955 & 202.7 \\
\hline Lombardy & Lecco & 805.6 & 337380 & 418.8 \\
\hline Lombardy & Lodi & 783.0 & 230198 & 230.2 \\
\hline Lombardy & Monza Brianza & 405.5 & 873935 & 2159.8 \\
\hline Lombardy & Milano & 1575.6 & 3250315 & 2028.9 \\
\hline Lombardy & Mantova & 2341.4 & 412292 & 176.1 \\
\hline Lombardy & Pavia & 2968.6 & 545888 & 183.9 \\
\hline Lombardy & Sondrio & 3195.8 & 181095 & 56.6 \\
\hline Lombardy & Varese & 1198.1 & 890768 & 743.5 \\
\hline Veneto & Belluno & 3610.2 & 202950 & 56.0 \\
\hline Veneto & Padova & 2144.1 & 937908 & 438.4 \\
\hline Veneto & Rovigo & 1819.3 & 234937 & 128.5 \\
\hline Veneto & Treviso & 2479.8 & 887806 & 358.5 \\
\hline Veneto & Venezia & 2472.9 & 853338 & 344.6 \\
\hline Veneto & Verona & 3096.3 & 926497 & 300.0 \\
\hline Veneto & Vicenza & 2722.5 & 862418 & 316.8 \\
\hline Emilia Romagna & Bologna & 3703.0 & 1014619 & 274.7 \\
\hline Emilia Romagna & Forlì-Cesena & 2378.4 & 394627 & 165.9 \\
\hline Emilia Romagna & Ferrara & 2635.1 & 345691 & 131.1 \\
\hline Emilia Romagna & Modena & 2688.0 & 705393 & 262.4 \\
\hline Emilia Romagna & Parma & 3447.4 & 451631 & 131.1 \\
\hline Emilia Romagna & Piacenza & 2585.8 & 287152 & 111.2 \\
\hline Emilia Romagna & Ravenna & 1859.4 & 389456 & 209.3 \\
\hline Emilia Romagna & Reggio Emilia & 2291.2 & 531891 & 232.1 \\
\hline Emilia Romagna & Rimini & 864.8 & 339017 & 392.4 \\
\hline Sicily & Agrigento & 3052.0 & 435137 & 142.5 \\
\hline Sicily & Caltanissetta & 2128.0 & 271758 & 130.0 \\
\hline Sicily & Catania & 3573.0 & 1108040 & 310.0 \\
\hline Sicily & Enna & 2574.0 & 164855 & 64.0 \\
\hline Sicily & Messina & 3266.0 & 627251 & 192.0 \\
\hline Sicily & Palermo & 5009.0 & 1253356 & 250.2 \\
\hline Sicily & Ragusa & 1623.0 & 320795 & 197.5 \\
\hline Sicily & Siracusa & 2124.0 & 397341 & 187.1 \\
\hline Sicily & Trapani & 2469.0 & 428192 & 173.4 \\
\hline
\end{tabular}

